\title{
Aggressive Angiomyxoma Of The External Ear In Children: An Extremely Rare Case
}

\author{
H. Mounji, M. Elbouderkaoui, M. Benfdil, Y. Rochdi, H. Nouri, and A. Raji
}

\begin{abstract}
Aggressive angiomyxoma is a mesenchymal tumor arising from connective tissues with a predilection to the female pelvic soft parts. Cervico-facial localization remains rare. We report here the first case of aggressive angiomyxoma of the external ear of a 7 year old patient, which was treated successfully by surgical excision. The clinical and pathologic features and radiological aspects of this tumor are discussed.
\end{abstract}

Index Terms-Aggressive, angiomyxoma, external ear, children.

\section{INTRODUCTION}

Angiomyxomas are uncommonly occurring mesenchymal tumors that are characterized by frequent local recurrences. The lesions nearly exclusively arise in the soft tissues of the perineum and the pelvis of adult women. Three types of angiomyxomas are recognized: aggressive, superficial, and angiomyofibroblastoma [1]. Cervico-facial localization remains rare $[1,2]$. To our knowledge, aggressive angiomyxomas of the external ear have not previously been reported in the literature. These tumors almost always affect adults in the third to fifth decades, with a marked predilection for females. Its presence in children is very rare [1].

\section{OBSERVATION}

A 7 years old patient was brought up to the ENT emergencies, with no particular pathological history including no trauma, presenting a swift right otorragia of low abundance, without other associated signs (no hypoacousia, no headache or dizziness).

The examination found a conscious and stable child. The otoscopic examination showed a small reddish-colored tumor emanating from the external auditory canal and protruding from the meatus (Fig. 1).

Published on June 15, 2020

H. Mounji, Mohammed VI university hospital center, Morocco. (corresponding e-mail: moun.houda ${ }^{@}$ gmail.com).

M. Elbouderkaoui, Mohammed VI university hospital center, Morocco.

M. Benfdil, Mohammed VI university hospital center, Morocco.

Y. Rochdi, Mohammed VI university hospital center, Morocco.

H. Nouri, Mohammed VI university hospital center, Morocco.

A. Raji, Mohammed VI university hospital center, Morocco.

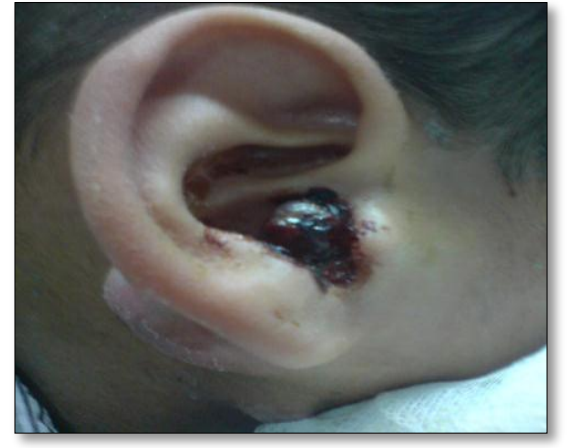

Fig 1. A reddish-colored tumor emanating from the external auditory canal

The cervical ganglionic areas were free. In view of this presentation, A computed tomography (CT) of the petrous temporal bones was requested, moreover, the mass increased rapidly in size and after 10 days was externalized by the external auditory canal and retro-auricular (Figure 2); thus assuming the appearance of an enormous tumor.

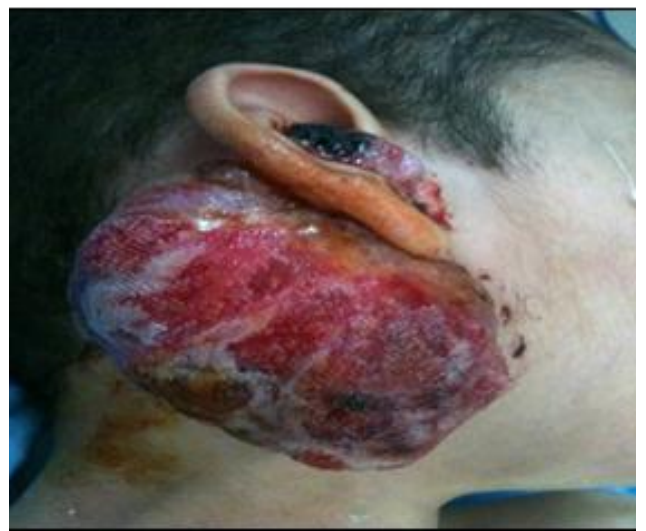

Fig. 2. Enormous tumor protruding from the external auditory meatus.

Temporal bones scan with cervical sections demonstrated a tissue filling the external auditory canal measuring $45 \times 40$ mm versus $25 \times 22 \mathrm{~mm}$, with a fleshy and cystic component and a spontaneously hyper dense content. This filling extended to the middle ear with attic, antrum, tympanic cavity and mastoid cells filling, nevertheless bypassing the ossicular chain. Outside, this mass extended to the superficial parotid lobe with subcutaneous infiltration (Fig. 3a, 3b).

The biological evaluation showed a leucocytosis at $12000 / \mathrm{mm} 3$. The sedimentation rate was normal. The chest $\mathrm{x}$-ray and abdominal ultrasound were not significantly abnormal.

A first biopsy was made, concluding after immunohistochemical study to a malignant mesenchymal tumor. 


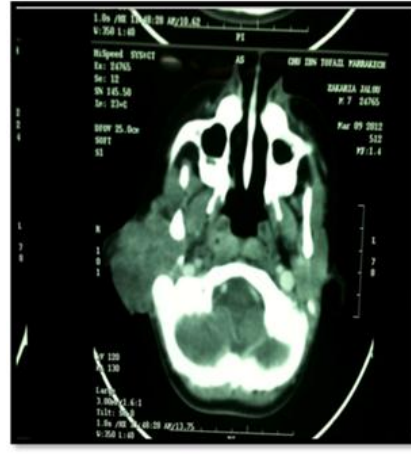

a)

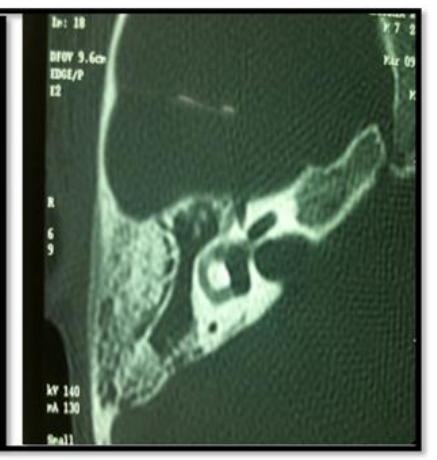

b)
Fig. 3. a) CT axial sections of temporal bone demonstrates a tissu filling the attic and antrum.

b) Axial CT scan of the neck showing extension to the superficial parotid.

This patient was treated by extensive tumor excision with radical mastoidectomy and superficial parotidectomy.

The histological study revealed spindle and myxoid cell proliferation, (Fig. 4).

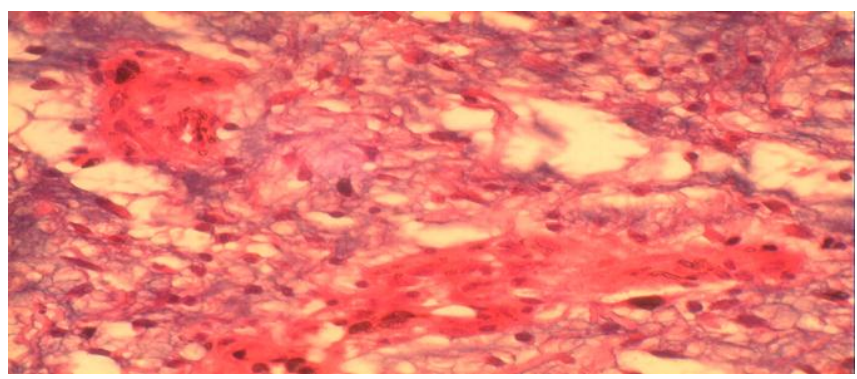

Fig. 4. Histological section showing spindle and myxoid cell

The immunohistochemical study concluded at an aggressive angiomyxoma.

The postoperative follow-up was normal, apart from a left conductive deafness ( $30 \mathrm{db}$ ). Regular follow-up of the child has been ensured (46 months and still counting) without any recurrence (Fig. 5).

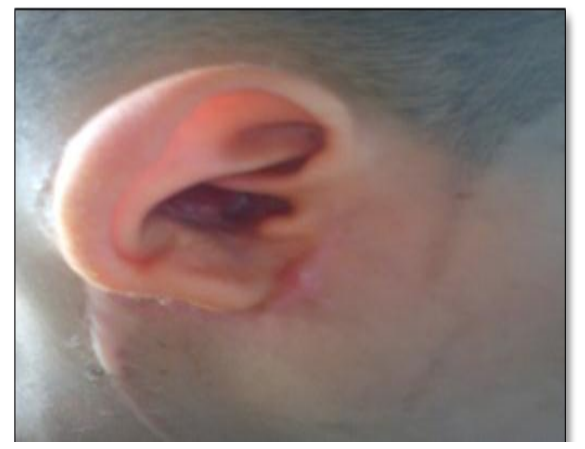

Fig. 5. The postoperative appearance at three months

\section{DISCUSSION}

Aggressive angiomyxoma, first described by Steeper and Rosai in 1983 [3] and now also referred to as "deep angiomyxoma" by the WHO [4], is a rare benign slow growing hypocellular soft tissue neoplasm composed of cytologically bland stellate and spindle shaped cells in a myxoid background, with a conspicuous vascular component. It is most commonly found in the vulvovaginal region of white females of reproductive age [5]. The cervico-facial localization remains exceptional [6]. The tumor usually presents itself as a mucous outgrowth that propagates insidiously but quickly infiltrating surrounding tissues [1]. This was the case of our patient.

Generally, tumor cells of aggressive angiomyxoma do not show cytonuclear atypia. Immunohistochemical studies show a significant positivity to vimentin and desmin [1], [7].

A cytogenetic study demonstrates that aggressive angiomyxoma is mainly due to a gene mutation located on chromosome 12 [8].

The differential diagnosis for aggressive angiomyxoma includes nerve sheath myxomas, myxoid smooth muscle tumors, myxoid malignant fibrous histiocytoma (myxofibrosarcoma), and the 2 other types of angiomyxomas $[1,3,6]$. Moreover, the immunohistochemical study does not always make it possible to hand-pick between these different histological forms which may all have a positivity to muscle markers $[1,4]$.

CT images are various and usually show a homogeneous mass, less dense than the muscle [9]. This is in line with our case.

The magnetic resonance imaging (MRI) aspect is characteristic, showing an iso or hypo-intense tumor compared to muscles in T1 and hyper-intense in T2. After injection of contrast, the mass enhances heavily and heterogeneously and may show less intense areas within the tumor [1], [10]. MRI has an important role in the diagnosis of tumor recurrence since the same radiological aspects are present in the areas of recurrence [10].

In the early and limited forms, a wide excision of the tumor is generally the guarantor of a curative treatment with few functional sequelae [1], [11]. This is the case of our patient.

However, the deep infiltrating sometimes makes complete excision difficult and dangerous. In all cases, surgery remains the better option, unless it is technically difficult or the risks involved are higher [12].

Some teams have attempted adjuvant chemotherapy [13]. Radiotherapy is not indicated in this type of tumor due to weak mitotic activity [1], [13]. It should be noted that no clearly defined and well-codified therapeutic approaches have been specified for the treatment of aggressive angiomyxomas [11].

Though aggressive angiomyxoma is benign, it is locally infiltrative with a high rate of recurrence $(71 \%$ at three years in one study) [12], with intervals from 9 to 180 months [3], [14]. The high rate of recurrence is thought to be secondary to inadequate primary excision [14]. Two cases of metastatic aggressive angiomyxoma have been reported [15], [16].

\section{CONCLUSION}

Aggressive angiomyxoma is a non-metastatic infectious mesenchymal tumor. The diagnosis must be precise in order to eliminate malignant sarcomatous proliferation. A wide surgical excision remains the therapeutic of choice. Recurrences are frequent and require regular monitoring after treatment. In summary, the clinical, histologic, and immunohistochemical findings of the lesion reported here were consistent with those of aggressive angiomyxoma. We report the first case of aggressive angiomyxoma of the external ear. 


\section{REFERENCES}

[1] Behranwala K A, Thomas JM. Agressive angiomyxoma : a distinct clinical entity. EJOS $2003 ; 29: 559-563$.

[2] Chen YK, Lin LM, Lin CC, et al: Myxoid tumor of the oral cavity with features of superficial angiomyxoma: Report of a case. J Oral Maxillofac Surg 56:379, 1998.

[3] Steeper TA, Rosai J. Aggressive angiomyxoma of the female pelvis and perineum. Report of nine cases of a distinctive type of gynecologic soft-tissue neoplasm. Am J Surg Pathol 1983;7:463-75.

[4] Tavassoli, FA.; Devilee, P., editors. World Health Organization Classification of Tumours: Pathology and Genetics of Tumours of the Breast and Female Genital Organs. IARC Press; Lyon: 2003. p. $305-$ 329.

[5] Papachristou DJ, Batistatou A, Paraskevaidis E, Agnantis NJ. Aggressive angiomyxoma of the vagina: a case report and review of the literature. Eur J Gynaecol Oncol 2004;25:519-21

[6] Yamashita Y, Tokunaga O, Goto M. Agressive Angiomyxoma of the Oral Floor : Report of a case. J Oral Maxillofac Surg 2004 ;62 :14291431.

[7] Dufau J P, Soulard R, Verine J, Liard O, Gros P. Une lésion récidivante de la lèvre $\mathrm{A}$ recurrent lesion of the lip. Ann Pathol $2002 ; 22: 339-40$.

[8] N. J. Rawlinson, W. West, Nelson M, and Julia A. Bridge. Aggressive Angiomyxoma with $\mathrm{t}(12 ; 21)$ and HMGA2 Rearrangement: Report of a Case and Review of the Literature. Cancer Genet Cytogenet. 2008 March ; 181(2): 119-124.

[9] Jeyadevan NN, Sohaib SA, Thomas JM, Jeyarajah A, Shepherd JH, Fisher C. Imaging features of aggressive angiomyxoma. Clin Radiol. 2003; 58(2):157-162. 15.

[10] Outwater EK, Marchetto BE, Wagner BJ, Siegelman ES. Aggressive angiomyxoma: findings on $\mathrm{CT}$ and $\mathrm{MR}$ imaging. AJR Am J Roentgenol. 1999; 172(2):435-438.

[11] Haldar K, Martinek IE, Kehoe S. Aggressive angiomyxoma: a case series and literature review. Eur J Surg Oncol. 2010;36(4):335-339.

[12] Chan YM, Hon E, Ngai SW, Ng TY, Wong LC. Aggressive angiomyxoma in females: is radical resection the only option? Acta Obstet Gynecol Scand. 2000; 79(3):216-220.

[13] Suleiman M, Duc C, Ritz S, Bieri S. Pelvic excision of large aggressive angiomyxoma in a woman: irradiation for recurrent disease. Int J Gynecol Cancer. 2006;16(suppl 1):356-360.

[14] Begin LR, Clement PB, Kirk ME, Jothy S, McCaughey WT, Ferenczy A. Aggressive angiomyxoma of pelvic soft parts: A clinicopathologic study of nine cases. Hum Pathol 1985;16:621-628.

[15] Siassi RM, Papadopoulos T, Matzel K. Metastasizing aggressive angiomyxoma. Engl J Med 1999;2:1772.

[16] Blandamura S, Cruz J, Faure Vergara L, Machado Puerto I, Ninfo V. Aggressive angiomyxoma: a second case of metastasis with patient's death. Hum Pathol 2003;34:1072-4. 